\title{
Translation and semiotics
}

Translation semiotics is on its way to becoming a discipline on its own. The present special issue does not aim to merge different ways of thinking about translation but instead to widen the field of thought and to highlight those keywords that would help us to understand translation activity better and to perceive the boundaries of translation semiotics.

The identity of translation semiotics as a discipline that has evolved in the contacts between translation studies and semiotics (of culture) can first be understood via mutual influences. Translation studies has already long ago turned to semiotics, and semiotics in its turn has made use of the concept of translation. It is natural that in the beginning, such processes bring about simplified treatments and terms become metaphorical. At the same time such metaphors enrich academic and critical thinking and have a significant role in the development of science.

Besides mutual contacts between two disciplines sometimes also the transdisciplinary aspect is important. The history of humanities and social sciences has always been accompanied by the fusion of historical sources: the same ideas have contributed to very different approaches. On the other hand new approaches look to history for support, or even receive their initial impulses for development from historical re-reading of certain authors or sources. Changes in the interdisciplinary field are accompanied by new historical relations, or in other words, overwriting of disciplinary histories.

A pioneer of translation semiotics and semiotranslation is Dinda Gorlée whose translation semiotics is based foremost on the deep familiarity with Charles Sanders Peirce's legacy but is also enriched with later authors in translation studies and semiotics (Roman Jakobson, Jiří Levý, Juri Lotman and others). While Peirce is already a "conceptualized" source for translation semiotics, the translationfocused re-reading of Jakobson has just only begun, and in the present issue almost all authors cover different aspects of his re-reading. Elin Sütiste creates an overview of the encyclopedic aspect of Jakobson's 
academic reception, focusing on the translation-related observations regarding his legacy. Peeter Torop draws attention to the distinction between communication and autocommunication in Jakobson's works and relates this distinction to Lotman's semiotics of culture. This relation also refers to an important aspect of the social appreciation of translation activity.

Since Peirce was an important author for Jakobson both implicitly and explicitly, their relation is of special interest for translation semiotics, and Bruno Osimo continues Gorlée's work in comparing these two authors. Edna Andrews and Elena Maksimova offer an extended model of the communication act, based on the fundamental principles given in Jakobson, Sebeok and Lotman, in order to specify important moments of the translation process. Silvi Salupere focuses on the concept of translation in the works of Lotman and thus introduces a metaphorical use of the concept of translation in translation semiotics. A fundamental principle of Lotman's semiotics of culture is regarding culture as an educating system. Translation as a certain type of texts of culture takes part in this process of educating bearers of culture, and as an example of this process, George Rückert analyses the educational aspects of translation activity in the period of Romanticism.

Looking at the contributions to this special issue against a wider background, it is not very trivial that Jakobson's terms - inter- and intralinguistic and intersemiotic translation - are used to characterize the different sides of a single translation process. The understanding of the psychological and semiotic mechanism of the translation process will depend on the understanding of the hierarchical relations between these three aspects. Besides treating these three ways of translating separately, the analysis of their relatedness and the projection of this entire term complex onto Jakobson's whole legacy has therefore become perhaps even more important. Thus a reason has arisen to revise Jakobson's terminology.

Jakobson's communication model that is well known also in translation studies acquires a somewhat new meaning when we remind ourselves that for the creator of this model communication meant not only interpersonal, but also intrapersonal communication. Also in Lotman's semiotics of culture the differentiation between communication and autocommunication is relevant: in this view, culture is continuously analyzing, describing, educating, developing itself, and for that purpose, creating autocommunicative or self-models for itself. 
These models are directed at generalizing the current situation in culture, explaining the necessity of change in culture, and developing theoretical possibilities - as today's theoretical model can already tomorrow be functional and practical. The entering of translations into culture and translation culture as an integral part of culture works according to the same principle. There are translations that support the existing situation and thus so to say belong to the culture's own repertoire, and then there are translations whose aim is to innovate culture. And of course there are also entirely "alien" translations that demonstrate the culture's capacity for translation and may acquire real contact with this culture only decades later. Translation activity is thus not only the mediation of natural languages and texts, but involves also creation of description languages and, with the help of this metalingual activity, organization of the relations between the own and the alien in culture.

The aim of this special issue is, on the one hand, to conceptualize disciplinary translation semiotics by expanding its boundaries, and on the other hand to bring to our attention such new relations in the history of science that may give new impulses to our contemporary science. By expanding the boundaries and revising history we can move towards disciplinary synthesis and begin talking more systematically of the disciplinary identity of translation semiotics.

Translation studies is a discipline studying translation and translating, and can define its identity facing the intersection between translation and translating. This intersection is the process of translation. If the object of translation studies is this process of translation, it can be analyzed and described. From the ontological viewpoint, the methodology of translation studies is based on the fact that no translation is fundamentally a unique text but one of many possibilities to render the original text. Original's singularity is thus in contrast with translation's plurality. From the epistemological viewpoint, this plurality requires a conceptual explanation or justification, which can be provided only by a theoretical model of translation process (see Torop 2007).

Besides translation's plurality, that is, the fundamental variability of translation texts, an important influence in the development of translation studies has been the movement towards "semioticalness" in the approach to language, the recognition of the semiotic nature of language. From the viewpoint of history of science, this means turning 
to history in search of innovation, as it is Jakobson's understanding of translation as being of interlinguistic, intralinguistic and intersemiotic kinds that makes possible the widening of the notion of language in translation studies and the broadening of the methodological perspective of this discipline. Methodological interpretation of Jakobson's translation types brings also semiotic thought into translation studies and draws understanding of translation closer to understanding of communication in general.

Let us recall that for Jakobson the linguistic and semiotic aspects of communication are interrelated. An integrated science of communication in Jakobson's opinion contains three disciplinary levels: "1) Study in communication of verbal messages = linguistics; 2) study in communication of any messages $=$ semiotics (communication of verbal messages implied); 3 ) study in communication $=$ social anthropology jointly with economics (communication of messages implied)" (Jakobson 1967: 666). Jakobson in another article distinguishes only two sciences from a semantic point of view - a science of verbal signs or linguistics and a science of all possible signs or semiotics (Jakobson 1974: 99). The interest of contemporary translation studies in the semiotic and cultural problems involved in translation is a good example of how the filtration of some disciplines in others starts to influence disciplinary identities.

The movement of translation semiotics towards disciplinarity is related, on the one hand, to understanding the relevance of translation in classical semiotics, and it is characteristic that translation has entered the research interests of scholars studying Ch. S. Peirce. Translation and mediation processes are the general basis for understanding semiosis and thus the notion of translation is acquiring increasingly greater concreteness in semiotic methodology. On the other hand, semiotics and especially semiotics of culture realize the need for discerning and typology of translation processes. Translation semiotics itself can be regarded as a discipline that deals with mediation processes between various sign systems, and, on the macro level, with culture as a translation mechanism. Against this background, we can see the relevance of discerning various translation processes: semiotic aspects of ordinary interlinguistic translation (for example, problems of the semiotic coherence of the text), metatextual translation, in- and intertextual translation, and extratextual translation. This means that Jakobson's tripartition is not sufficient for discerning the cultural 
variety of translation processes, although it has provided its conceptual basis. The ontology of translation semiotics rests on the recognition that culture works in many respects as a translation mechanism and that mediation in culture involves both communication and autocommunication. This means that translation semiotics is an important instrument in interpreting communication processes as cultural autocommunication. Culture translates itself to itself in order to constitute and keep its identity. The epistemology of translation semiotics is based on the distinction of sign systems' hierarchies, translatability and translation capacity, and the comparison with intertextual, transmedial and intersemiotic processes in culture. As such, translation semiotics responds to the interests of both translation studies and semiotics of culture, while at the same time shaping its own disciplinary identity.

\section{References}

Jakobson, Roman 1985 [1974]. Communication and society. In: Jakobson, Roman, Selected Writings. VII. Contributions to Comparative Mythology. Studies in Linguistics and Philology, 1972-1982. Rudy, Stephen (ed.). Berlin: Mouton Publishers, 98-100.

— 1971 [1967]. Linguistics in relation to other sciences. In: Jakobson, Roman, Selected Writings. II. Word and Language. The Hague: Mouton, 655-695.

Torop, Peeter 2007. Methodological remarks on the study of translation and translating. Semiotica 163(1/4): 347-364.

Peeter Torop ${ }^{l}$

1 Author's address: Department of Semiotics, University of Tartu, Tiigi St. 78, 50410 Tartu, Estonia; e-mail: torop@ut.ee. 
258 Peeter Torop 